\title{
Methane Photochemistry and Haze Production on Neptune
}

\author{
P. N. ROMANI ${ }^{1}$ \\ Mail Code 693.2, NASA Goddard Space Flight Center, Greenbelt, Maryland 20771
}

AND

S. K. ATREYA

Department of Atmospheric and Oceanic Science. The University of Michigan, Ann Arbor, Michigan 48109

Received August 5, 1987; revised November 30, 1987

A numerical model was used to study methane photochemistry in the stratosphere of Neptune. The observed mixing ratio of methane, $2 \%$, forces photolysis to occur near the $\mathrm{CH}_{4}$ homopause. For an assumed nominal value of the eddy mixing coefficient of $10^{6} \mathrm{~cm}^{2}$ $\sec ^{-1}$ at the $\mathrm{CH}_{4}$ homopause, the predicted average mixing ratios of $\mathrm{C}_{2} \mathrm{H}_{6}$ and $\mathrm{C}_{2} \mathrm{H}_{2}, 1.5$ $\times 10^{-6}$ and $6 \times 10^{-7}$, respectively, agree well with observations in the infrared. The acetylene and ethane abundances are weakly dependent upon the strength of the eddy mixing and directly proportional to it. Haze production from methane photochemistry results from the formation of hydrocarbon ices and polyacetylenes. The calculated mixing ratios of $\mathrm{C}_{2} \mathrm{H}_{6}, \mathrm{C}_{2} \mathrm{H}_{2}$, and $\mathrm{C}_{4} \mathrm{H}_{2}$ are large enough to cause condensation to their respective ices near the tropopause. These hazes are capable of providing the necessary aerosol optical depth at the appropriate pressure levels required by observations of Neptune in the visible and near IR. Polyacetylene formation from $\mathrm{C}_{2} \mathrm{H}_{2}$ photolysis is limited by the low quantum yield of dissociation for acetylene, efficient recycling of its photolysis products by the other hydrocarbons, and the greatly reduced solar flux at Neptune. Comparisons of model predictions to Uranus show both a lower ratio of polyacetylene production to hydrocarbon ice and a lower likelihood of $U V$ postprocessing of the acetylene ice to polymers on Neptune compared to Uranus. This is in agreement with the observed difference in the single scattering albedo of the stratospheric aerosols in the visible between Uranus and Neptune, with the aerosols on Neptune being brighter. 1988 Academic Press, Inc.

\section{INTRODUCTION}

The photochemistry of methane has been studied extensively for Jupiter (Strobel 1969, 1973, 1975, Atreya et al. 1981, Gladstone 1982) and Saturn (Waite 1981, Atreya 1982, Atreya et al. 1984). For Uranus, the preliminary modeling of Atreya and Ponthieu (1983) and the subsequent more detailed modeling by Romani (1986) have been used to determine the eddy mixing coefficient (Atreya et al. 1986, Herbert et al.

I NAS/NRC Resident Research Associate.
1987) and the nature of the stratospheric aerosols (Pollack et al. 1987). But only preliminary work has been reported for Neptune (Romani and Atreya 1984, Atreya 1986). In this paper the photochemistry of methane in the stratosphere of Neptune and subsequent aerosol production are presented. Special emphasis will be placed on stratospheric acetylene and ethane abundances, haze production, comparison to Uranus, and conditions liable to be present at the time of the Voyager 2 encounter of Neptune.

Methane, ethane, and acetylene have 
been detected in emission in the infrared from Neptune (Macy and Sinton 1977, Orton et al. 1983, 1987). The photolysis of methane in the stratosphere of Neptune produces ethane and acetylene, so numerical modeling of the photochemistry should be able to reproduce the observed mixing ratios of $\mathrm{C}_{2} \mathrm{H}_{2}$ and $\mathrm{C}_{2} \mathrm{H}_{6}$. This procedure is sensitive to the amount of eddy mixing and presently allows some constraints to be placed upon the value of the eddy mixing coefficient. Numerical modeling also produces more detailed profiles of the hydrocarbons than can be deduced from the IR. This is important as these gases are IR active and affect the thermal structure of the stratosphere (Courtin et al. 1979, Appleby 1986). Furthermore, height profiles of the hydrocarbons are needed to derive the strength of atmospheric vertical mixing from Voyager UVS occultation data.

On Neptune, the model-predicted abundances of acetylene and ethane in the lower stratosphere are much greater than their maximum allowable abundances from the equilibrium saturation vapor pressures over their respective ices. Thus, we expect ice haze formation in the lower stratosphere of Neptune. Methane photochemistry has also been proposed as a source of polyacetylene aerosols (Gladstone 1982, Allen et al. 1980). These aerosols, ices and polyacetylenes, are capable of affecting the visibility (Bergstralh et al. 1987), albedo (Lockwood and Thompson 1986), and thermal structure of the lower stratosphere (Appleby 1986). Other possible sources of aerosols, $\mathrm{PH}_{3}$ and/or $\mathrm{NH}_{3}$ photochemistry (West et al. 1986), will not be active because of the removal of the parent species in the lower troposphere by condensation (Weidenschilling and Lewis 1973, Romani 1986). Hydrocarbon ice formation and polyacetylene production also occur on Uranus (Romani and Atreya 1986, Pollack et al. 1987), so modeling must be able to reproduce the observed differences of the two planets' stratospheric aerosols (Bergstralh and Baines 1984, Bergstralh et al. 1987).
The paper is organized into the following sections. The methane photochemistry model is described in Section II. The altitude profiles of methane, ethane, and acetylene calculated by the photochemical model are discussed in Section III. In Section IV, the aerosols produced from methane photochemistry are analyzed. The results are summarized in Section V.

\section{PHOTOCHEMICAL MODEL}

\section{A. Numerical Procedure}

The numerical model solves the coupled continuity equations for methane and its photolysis products by using an iterative Newton-Raphson technique (Ames 1969). Fixed-point boundary conditions and a convergence criteria of $1 \%$ were used for all studies. The model assumes a steady-state condition and a horizontally averaged atmosphere so the continuity equation for the $i$ th species becomes

$$
d F_{i} / d z=P_{i}-L_{i},
$$

where $z$ is the altitude, $F_{i}$ is the flux of species $i$ in molecules $\mathrm{cm}^{-2} \mathrm{sec}^{-1}, P_{i}$ is the chemical production rate and $L_{i}$ is the chemical loss rate of species $i$ both in units of molecules $\mathrm{cm}^{-3} \mathrm{sec}^{-1}$. In the model, methane $\left(\mathrm{CH}_{4}\right)$, methyl radical $\left(\mathrm{CH}_{3}\right)$, ethylene $\left(\mathrm{C}_{2} \mathrm{H}_{4}\right)$, acetylene $\left(\mathrm{C}_{2} \mathrm{H}_{2}\right)$, ethane $\left(\mathrm{C}_{2} \mathrm{H}_{6}\right)$, and atomic hydrogen $(\mathrm{H})$ undergo both transport and photochemical reactions. The radicals, methylidyne $(\mathrm{CH})$, ground-state methylene $\left({ }^{3} \mathrm{CH}_{2}\right)$, excited methylene $\left({ }^{1} \mathrm{CH}_{2}\right)$, ethynyl $\left(\mathrm{C}_{2} \mathrm{H}\right)$, vinyl $\left(\mathrm{C}_{2} \mathrm{H}_{3}\right)$, and ethyl $\left(\mathrm{C}_{2} \mathrm{H}_{5}\right)$, are assumed to be in photochemical equilibrium. The mixing ratio profile of diacetylene, $\mathrm{C}_{4} \mathrm{H}_{2}$ (the first polyacetylene produced from acetylene photolysis), was solved separately by using as input the already converged profiles of the other hydrocarbons and eddy mixing. This is justified by the weak feedback of diacetylene photolysis into the photochemistry of the other hydrocarbons. As diacetylene is not a radical, it also undergoes both transport and photochemical reactions in 


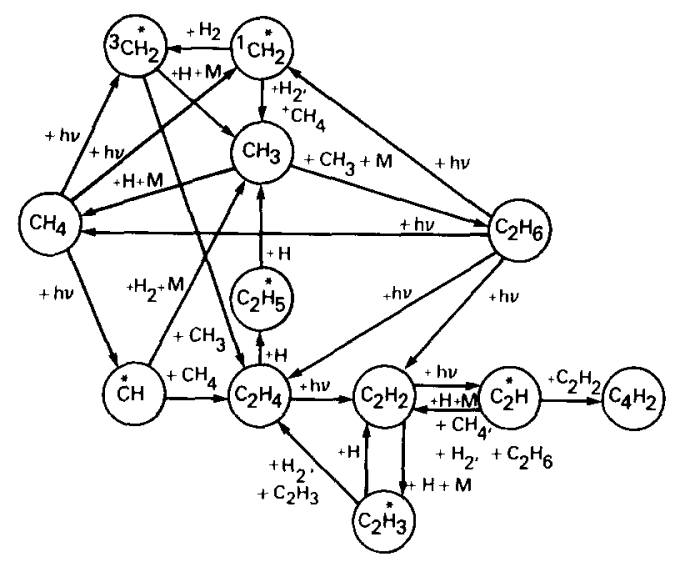

FIG. 1. Reaction pathways for methane photochemistry. A * denotes a radical assumed to be in local photochemical equilibrium. Adapted from Atreya and Romani (1985), with the exception of rightmost pathways producing $\mathrm{C}_{4} \mathrm{H}_{2}$.

the model. From comparison of results to observations of the hydrocarbons in the stratospheres of Jupiter, Saturn, and Uranus, we estimate a maximum uncertainty of a factor of 2 in the mixing ratios computed by the photochemical model (Atreya et al. 1981, 1986, Atreya 1982, Herbert et al. 1987).

\section{B. Photochemistry}

In this section the photochemical pathways in methane photolysis and hydrocarbon production are outlined. The relative importance of these pathways for Neptune will be discussed under Results. A schematic of the photochemistry used in our model is shown in Figs. 1 and 2. As Neptune is a rapid rotator, the photolysis rates used in the model are diurnal averages.

The photolysis of methane is carried out primarily at Lyman- $\alpha$ due to the large solar flux at this wavelength. This produces approximately equal quantities of ${ }^{1} \mathrm{CH}_{2}$ and ${ }^{3} \mathrm{CH}_{2}$. These radicals then rapidly react with $\mathrm{H}_{2}$ and $\mathrm{H}$ to produce principally $\mathrm{CH}_{3}$. Direct production of $\mathrm{CH}_{3}$ from methane photolysis is quantum-mechanically forbidden and this has been confirmed by experiment (Slanger 1982). The other direct pho- tolysis product of methane is the $\mathrm{CH}$ radical which quickly reacts with methane to produce ethylene.

The primary fate of the methyl radical is to recycle to $\mathrm{CH}_{4}$, but it also self-reacts and produces $\mathrm{C}_{2} \mathrm{H}_{6}$. Ethane is chemically stable and is only destroyed by photolysis, producing acetylene or ethylene, or removed by eddy mixing. Photolysis proceeds slowly for $\mathrm{C}_{2} \mathrm{H}_{6}$ as it absorbs only in the same spectral region as methane. Thus, $\mathrm{CH}_{4}$ acts as an ultraviolet shield for ethane allowing its relative abundance to build up before its eventual removal by eddy mixing.

The ethylene produced by the above reactions is destroyed rapidly by reacting with $\mathrm{H}$ and by photolysis. Unlike ethane, ethylene has a significant cross section of absorption beyond the methane cutoff at $1500 \AA$, so photolysis is not hampered by methane shielding.

The acetylene produced from both $\mathrm{C}_{2} \mathrm{H}_{6}$ and $\mathrm{C}_{2} \mathrm{H}_{4}$ photolysis is removed only by photolysis and eddy mixing. $\left(\mathrm{C}_{2} \mathrm{H}_{3}\right.$ formed by the three-body reaction of $\mathrm{H}$ with $\mathrm{C}_{2} \mathrm{H}_{2}$ primarily recycles to acetylene by reacting with H.) Even though acetylene, like ethylene, has a significant cross section in the UV beyond the methane cutoff, photolysis

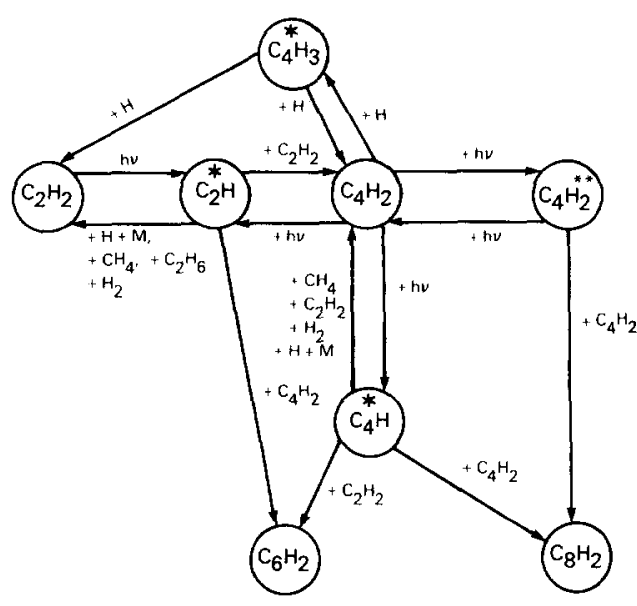

FIG. 2, Reaction pathways for diacetylene photolysis. $\mathrm{A} *$ denotes a radical assumed to be in local photochemical equilibrium; ** denotes a metastable excited species. Taken from Pollack et al. (1987). 
is not an efficient sink for $\mathrm{C}_{2} \mathrm{H}_{2}$. The quantum yield for dissociation for acetylene is small and its photolysis products are rapidly recycled back to acetylene by the other hydrocarbons and $\mathrm{H}_{2}$.

The photochemistry of diacetylene has also been included (Fig. 2). The reaction scheme is similar to the one of Yung et al. (1984), but we have made use of the recent laboratory measurements of Glicker and Okabe (1987) for the cross section of absorption and quantum yields of $\mathrm{C}_{4} \mathrm{H}_{2}$ photolysis. After undergoing photolysis, diacetylene either gives back acetylene, recycles, or reacts to produce higher order polyacetylenes. Unfortunately there are no laboratory measurements of the reactions involving the $\mathrm{C}_{4} \mathrm{H}$ radical or of $\mathrm{C}_{2} \mathrm{H}$ with $\mathrm{C}_{4} \mathrm{H}_{2}$. These reaction rates have been estimated in the manner of Yung et al. The reaction of ground-state $\mathrm{C}_{4} \mathrm{H}_{2}$ with its metastable excited state has been assumed to be the collisional rate. The lifetime of the metastable excited state of $\mathrm{C}_{4} \mathrm{H}_{2}$ against radiative relaxation has been assumed to be 1 msec. The data of Glicker and Okabe yield only a lower limit, and our value represents an upper limit. In our studies for Neptune the excited metastable pathway for polyacetylene formation was never important.

\section{Flux Equation}

The flux term in the continuity equation used in the numerical model includes contributions from both eddy mixing and molecular diffusion. This is because the region of interest for methane photochemistry extends from the tropopause, where the atmosphere is well mixed, to the methane homopause. This expression for the flux of the $i$ th species, $F_{i}$, is

$$
\begin{array}{r}
F_{i}=-\left(K+D_{i}\right) *\left[d n_{i} / d z+\left(n_{i} / T\right) * d T / d z\right. \\
\left.+n_{i} *\left(1 / H+1 / H_{i}\right)\right],
\end{array}
$$

where $K$ is the eddy mixing coefficient, $T$ the atmospheric temperature, $H$ the mixed atmosphere scale height, and $D_{i}, n_{i}$, and $H_{i}$ are, respectively, the molecular diffusion coefficient, number density, and scale height of the $i$ th species. The homopause for the $i$ th species is defined to be where $D_{i}$ $=K$.

The molecular diffusion coefficients for the hydrocarbons and atomic hydrogen in $\mathrm{H}_{2}$ and $\mathrm{He}$ used in the model are from Marrero and Mason (1972) and the references contained therein. These background-gasdependent diffusion coefficients are then combined to produce effective diffusion coefficients for each species in the model atmosphere.

The eddy mixing coefficient was chosen to vary with the reciprocal of the square root of the atmospheric number density. This is in agreement with theoretical calculations of the variation of $K$ in a temperature inversion region (Lindzen 1971). Previous analyses of $K$ in the stratospheres of Jupiter, Saturn, and Uranus are also compatible with this variation of $K$ (Atreya et al. 1981, 1986, Atreya 1982, Herbert et al. 1987). The values of $K$ quoted in this paper hereafter will be their values at the $\mathrm{CH}_{4}$ homopause in $\mathrm{cm}^{2} \mathrm{sec}^{-1}$.

\section{Model Atmosphere}

The thermal structure for the Neptune stratosphere (Fig. 3) is consistent with the perturbed equilibrium model of Tokunaga et al. (1983). They constrained a theoretical radiative transfer profile of Appleby (1986) to agree with their observations of Neptune in the infrared. This temperature-pressure profile is in agreement with the later observations of Orton et al. (1983) at other wavelengths in the IR. This profile was extended to the microbar region by assuming the temperature was linear with log pressure. The microbar temperature, $155^{\circ} \mathrm{K}$, was chosen to agree with the mean temperature derived from the stellar occultation observations of French et al. (1983). Above the microbar level the atmosphere was assumed to be isothermal with this temperature. An approximately solar composition background atmosphere $\left(90 \% \mathrm{H}_{2}\right.$ and $\left.10 \% \mathrm{He}\right)$ was chosen in conformity with Tokunaga et al.

Because the observations of French et al. 


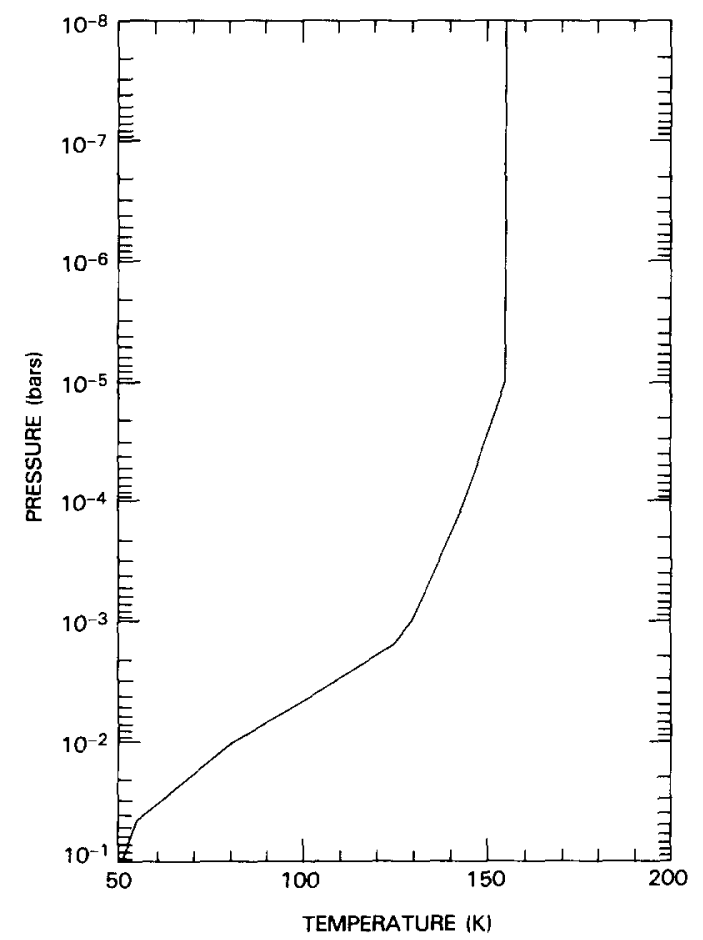

FIG. 3. Adopted thermal structure for the stratosphere of Neptune.

(1983) indicate a range of temperatures from 130 to $160^{\circ} \mathrm{K}$, the model was run with an extreme low microbar temperature of $125^{\circ} \mathrm{K}$ to determine what effect this would have on the hydrocarbon abundances. Differences in the mixing ratios of methane, acetylene, and ethane between the runs were less than a factor of 2 at all levels. The only noticeable effect of decreasing the temperature at the microbar level was to compress the atmosphere and so lower the altitude above the tropopause where methane photolysis takes place. The greatest effect of uncertainties in the temperaturepressure profile will be for the location of the ice hazes in the lower stratosphere. This is because the vapor pressures of the hydrocarbons are exponentially dependent upon temperature. Small changes in temperature will greatly change the atmospheric pressure level at which they condense; this will be discussed more later on.

\section{E. Solar Flux}

The solar flux used in the model is from the measured solar fluxes at $1 \mathrm{AU}$ of $\mathrm{He}$ roux and Hinteregger (1978) and Mount and Rottman (1981). These fluxes were then scaled to the Sun-Neptune distance. Solar maximum fluxes were used in the standard model to reproduce conditions at the time of the Voyager 2 encounter in 1989. The spectrum runs from 1000 to $3000 \AA$ and is binned in $10-\AA$ intervals with a separate bin for Lyman- $\alpha$. The short wavelength cutoff is due to absorption by $\mathrm{H}_{2}$ above the hydrocarbons, and the long wavelength cutoff is because of the decrease in the absorption cross sections of the hydrocarbons. A case with solar minimum fluxes was run to investigate the variation of the hydrocarbons with solar flux.

\section{F. Solar Zenith Angle vs Latitude, and Diurnal Variation}

At the time of the Voyager 2 encounter with Neptune in 1989 it will be near summer solstice for the southern hemisphere of the planet. Currently, the planned Earth and solar occultations will take place at both approximately $62^{\circ} \mathrm{N}$ and $26^{\circ} \mathrm{S}$. The diurnal average of the cosine of the solar zenith angle as a function of latitude was calculated using the following relationship from Liou (1980):

$$
\begin{aligned}
\cos (\xi)=1 / h * & {[h * \sin (\lambda) * \sin (\delta)} \\
& +\cos (\lambda) * \cos (\delta) * \sin (h)],
\end{aligned}
$$

where $\xi$ is the solar zenith angle, $h$ the halflength of the illuminated day in radians, $\lambda$ the planetary latitude, and $\delta$ the solar declination. The half-length of the illuminated day is given by the following relationships also from Liou:

$$
\begin{aligned}
\chi=-\tan (\delta) * & \tan (\lambda) \\
h=\cos ^{-1}(\chi), & \text { if } \chi \geq 1, \quad \text { then } h=0, \\
& \text { if } \chi \leq-1, \quad \text { then } h=\pi .
\end{aligned}
$$

It is the average cosine that is important for the photochemistry, not the average solar 
TABLE I

Solar Zenith Angle and Diurnal Variation of SunLight vs Latitude

\begin{tabular}{lcc}
\hline Latitude & $\begin{array}{c}\text { Solar zenith } \\
\text { angle }\end{array}$ & $\begin{array}{c}\text { Diurnal variation } \\
\text { of sunlight }\end{array}$ \\
\hline $80^{\circ} \mathrm{S}$ & $60^{\circ}$ & No \\
$25^{\circ} \mathrm{S}$ & $50^{\circ}$ & Yes \\
$45^{\circ} \mathrm{N}$ & $80^{\circ}$ & Yes
\end{tabular}

"At southern summer solstice latitudes below $60^{\circ} \mathrm{S}$ are in perpetual sunshine.

zenith angle. The solar zenith angles corresponding to the above average of the cosine and the variation in diurnal solar illumination for three representative latitudes on Neptune are given in Table I. Model runs corresponding to all three latitudes were done to investigate potential latitudinal variations of the hydrocarbon abundances due to changes in the solar illumination. Included are the southern occultation point, a high southern latitude in perpetual daylight, and a northern latitude. (The northern oc- cultation point will be in the polar night, so a model run with a solar zenith angle of $80^{\circ}$ was substituted for it.)

\section{PHOTOCHEMISTRY RESULTS}

\section{A. Variation as a Function of $K$}

The methane mixing ratio on Neptune as a function of probable values of the eddy mixing coefficient is shown in Fig. 4. The mixing ratio in the lower stratosphere is $2 \%$. This is in agreement with the current degree of supersaturation of methane inferred from measurements in the infrared (Orton et al. 1983, 1987) and from radiative equilibrium modeling of the stratosphere (Appleby 1986). The relative locations of the methane homopause for these values of $K$, and the corresponding levels where an optical depth of one is reached at Lyman- $\alpha$ $(\tau=1)$ are listed in Table II. For a methane mixing ratio of $2 \%, \tau=1$ would occur at $10^{-8}$ bar $(715 \mathrm{~km}$ above the tropopause), well above any of these homopause levels. Because of the large abundance of methane

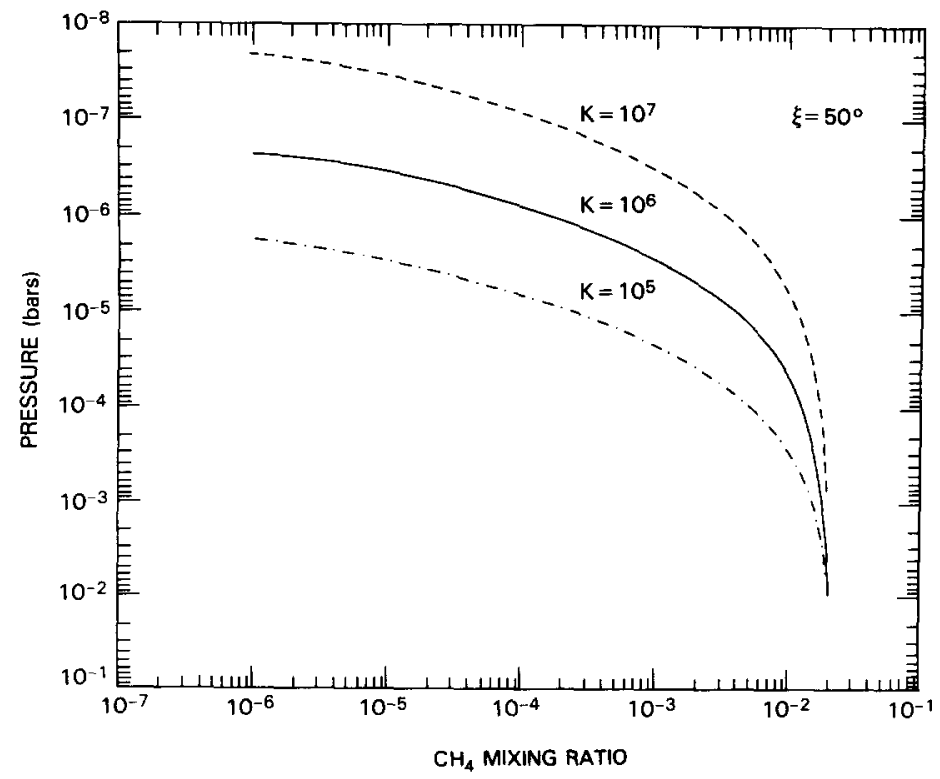

FIG. 4. The mixing ratio profile of methane as a function of the eddy mixing coefficient for a solar zenith angle of $50^{\circ}$. The value given for $K$ is the value it has at the methane homopause in $\mathrm{cm}^{2} \mathrm{sec}^{-1} . K$ is assumed to be proportional to the inverse square root of the atmospheric number density. 
TABLE II

Homopause Levels and CoRResponding Levels WHERE $\tau=1$ AT LYMAN- $\alpha$ AS A FUNCTION OF THE Eddy Mixing Coefficient

\begin{tabular}{|c|c|c|c|c|}
\hline \multirow{3}{*}{$\begin{array}{c}K \\
\left(\mathrm{~cm}^{2} \sec ^{-1}\right)\end{array}$} & \multicolumn{2}{|c|}{ Homopause level } & \multirow{2}{*}{\multicolumn{2}{|c|}{$\begin{array}{c}\text { Level where } \\
\boldsymbol{\tau}=1 \text { at } \\
\text { Lyman- } \alpha\end{array}$}} \\
\hline & \multirow[t]{2}{*}{$(\mathrm{km})^{a}$} & \multirow[t]{2}{*}{ (bar) } & & \\
\hline & & & $(\mathrm{km})^{a}$ & (bar) \\
\hline $10^{5}$ & 430 & $2.6 \times 10^{-6}$ & 375 & $7.4 \times 10^{-6}$ \\
\hline $10^{6}$ & 550 & $2.7 \times 10^{-7}$ & 460 & $1.5 \times 10^{-6}$ \\
\hline $10^{7}$ & 675 & $2.5 \times 10^{-8}$ & 535 & $3.6 \times 10^{-7}$ \\
\hline
\end{tabular}

"Zero for altitude is the tropopause taken to be at the 100 mbar pressure level, which is approximately $65 \mathrm{~km}$ above the 1-bar level.

in the stratosphere of Neptune, photolysis cannot proceed efficiently until near the homopause where gravitational separation depletes the atmosphere of methane.

From these values of the eddy mixing coefficient a nominal value must be selected. There is no single direct observation that uniquely constrains the value of $K$ in the stratosphere of Neptune, but we can infer limits on its value from a variety of observations.

There is abundant evidence that the lower stratosphere of Neptune is dynamically active. The temporal change of the brightness in the visible spectrum of Neptune observed by Joyce et al. (1977) can be satisfactorily explained by an increase in aerosols in the lower stratosphere and their eventual removal by sedimentation (Pilcher 1977). More recent observations have revealed spatial inhomogeneities in the aerosols across the disk of Neptune and temporal variations on the order of days (Terrile and Smith 1983, Baines et al. 1987, Bergstralh et al. 1987). The supersaturation of methane in the stratosphere probably results from methane ice clouds, which form in the upper troposphere (at approximately the 1.4-bar level, Romani 1986), convectively penetrating the tropopause and depositing methane ice in the lower stratosphere which then sublimates (Appleby 1986). Simple diffusion of the $\mathrm{CH}_{4}$ ice crystals through the tropopause is not likely to be the source of the supersaturation. The sedimentation lifetime of even $0.1-\mu \mathrm{m}$ crystals is faster by an order of magnitude than any likely eddy mixing lifetime.

It is important to note that no such variations in brightness have been observed for Uranus and that methane is saturation-limited in the stratosphere. Based on this, we argue that the minimum eddy mixing coefficient on Neptune is as great as it is on Uranus, $10^{4}$ (Herbert et al. 1987), and probably greater.

Less direct evidence for Neptune having a greater eddy mixing coefficient than Uranus is that Neptune has a strong internal heat source, approximately twice that of absorbed solar radiation (Orton and Appleby 1984). Jupiter and Saturn also have internal heat sources and have eddy mixing coefficients of approximately $10^{6}$ and $10^{8}$ $\mathrm{cm}^{2} \mathrm{sec}^{-1}$, respectively, at the methane homopause (Atreya 1986). Uranus, which possesses little, if any, internal heat source (Pearl et al. 1987), has the lowest rate of eddy mixing in its stratosphere of all of the Jovian planets. This correlation between the strength of an internal heat source and the strength of eddy mixing probably arises through the generation of gravity waves in the lower atmosphere which break in the stratosphere and are known to be the source of the eddy mixing there (Lindzen 1971, 1981, Fritts 1984). At this time, however, the exact link is not known.

Based on the preceding arguments, we adopted a nominal value of $K$ for Neptune similar to that of Jupiter, $10^{6} \mathrm{~cm}^{2} \mathrm{sec}^{-1}$. The derived abundances of $\mathrm{C}_{2} \mathrm{H}_{2}$ and $\mathrm{C}_{2} \mathrm{H}_{6}$ detected in emission in the infrared are consistent with this choice. The mixing ratio profiles of ethane and acetylene as a function of the eddy mixing coefficient are shown in Figs. 5 and 6, respectively. Ethane was first detected in emission in the stratosphere of Neptune by Macy and Sinton (1977) and Gillett and Rieke (1977). Macy (1980) derived an abundance of $\mathrm{C}_{2} \mathrm{H}_{6}$ relative to $\mathrm{H}_{2}$ of $10^{-6}$ with an uncertainty 


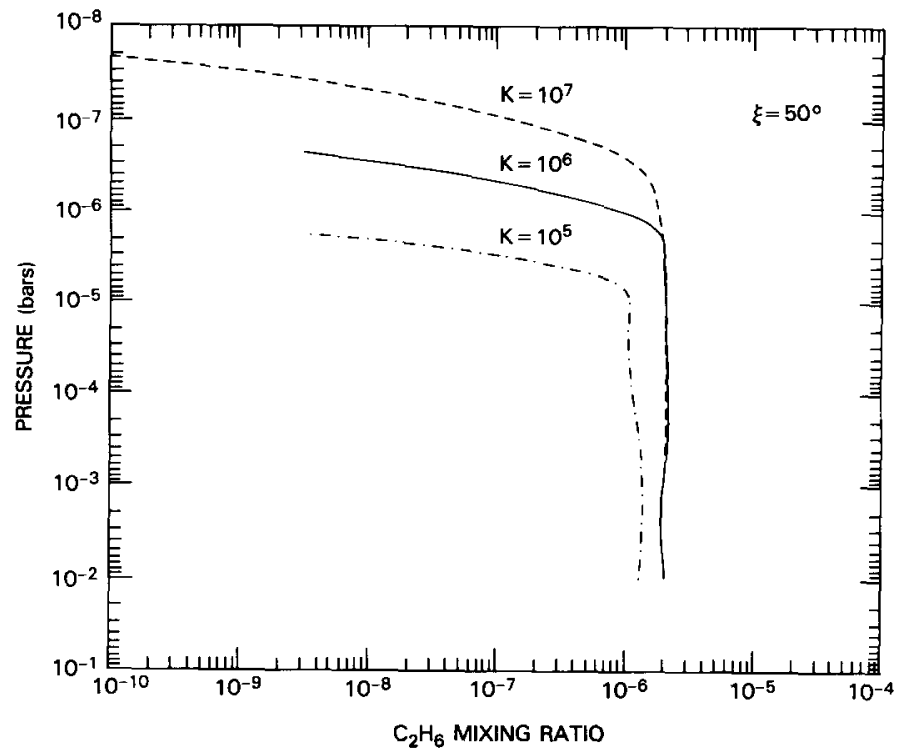

FIG. 5. Same as Fig. 4, but for ethane.

factor of 5. Subsequently Orton et al. (1983) and remains constant. (For our model atinferred an ethane mixing ratio of $3 \times 10^{-6}$, mosphere this turnover will occur at $\approx 1.3$ and most recently Orton et al. (1987) have $\times 10^{-2}$ bar.) As can be seen in Fig. 5, an inferred $6 \times 10^{-6}$ with an uncertainty factor eddy mixing coefficient of $10^{6}$, which is inof 3.2. These last two mixing ratios assume distinguishable from one of $10^{7}$, gives better that the ethane abundance follows its satu- agreement than one of $10^{5}$. Orton et al. ration law in the lower stratosphere until it (1987) have deduced a maximum mixing rareaches the above maximum mixing ratios tio of $\mathrm{C}_{2} \mathrm{H}_{2}$ of $9 \times 10^{-7}$ with an uncertainty

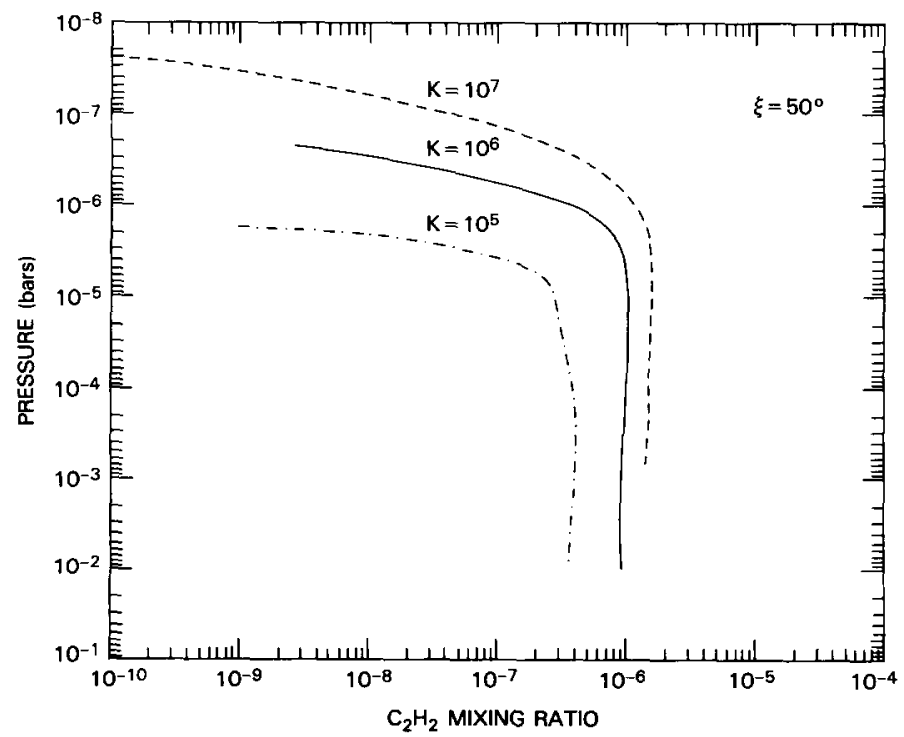

Fig. 6. Same as Fig. 4, but for acetylene. 


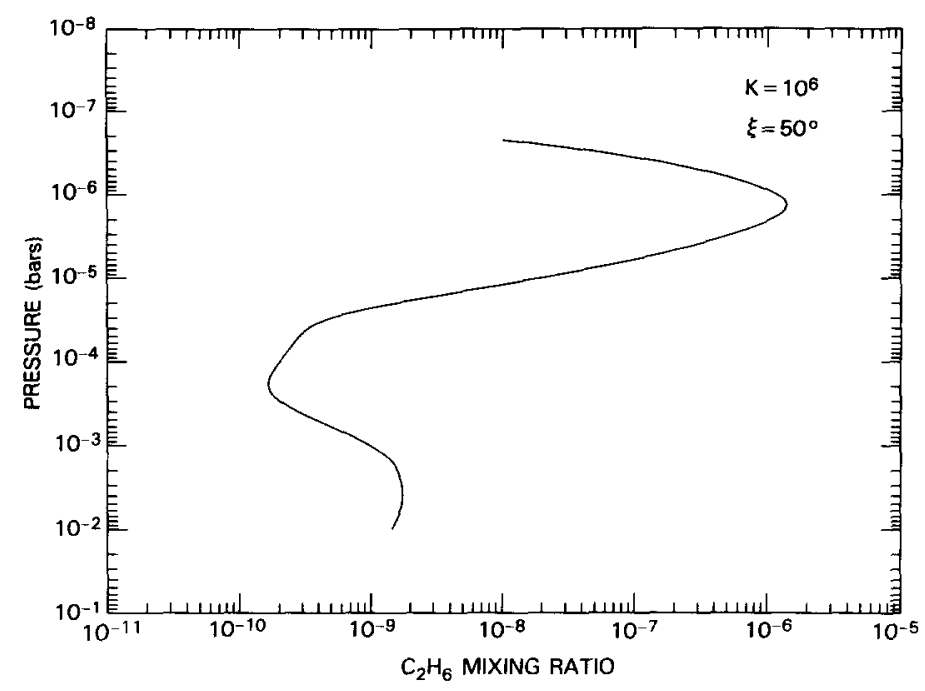

FIG. 7. The mixing ratio profile of ethylene for $K=10^{6} \mathrm{~cm}^{2} \mathrm{sec}^{-1}$, and a solar zenith angle of $50^{\circ}$.

of a factor of 5 , assuming that the distribution of acetylene is the same as that of ethane. (In our model atmosphere, and for this mixing ratio, acetylene will depart from its saturation curve at $\approx 9 \times 10^{-3}$ bar.) From Fig. 6 we can see that a $K$ of $10^{6}$ also gives good agreement to the acetylene observations.

Orton et al. (1987) interpret emission near $13.5 \mu \mathrm{m}$ in the spectrum of Neptune as being from ethylene with a maximum mixing ratio of approximately $3 \times 10^{-9}$, assuming that it also follows its saturation curve until this mixing ratio is reached. The mixing ratio profile for $\mathrm{C}_{2} \mathrm{H}_{4}$ with $K$ of $10^{6}$ is shown in Fig. 7. Though the mixing ratio profile of ethylene is more complicated than the one used by Orton et al., the model abundance in the lower stratosphere of $2 \times$ $10^{-9}$ is close to their inferred value. This relatively large ethylene abundance in the lower stratosphere is coupled to the acetylene abundance. Acetylene is the source of ethylene in the lower stratosphere via the net reaction

$$
\begin{aligned}
2\left(\mathrm{H}+\mathrm{C}_{2} \mathrm{H}_{2}+M\right. & \left.\rightarrow \mathrm{C}_{2} \mathrm{H}_{3}+M\right) \\
\mathrm{C}_{2} \mathrm{H}_{3}+\mathrm{C}_{2} \mathrm{H}_{3} & \rightarrow \mathrm{C}_{2} \mathrm{H}_{2}+\mathrm{C}_{2} \mathrm{H}_{4} \\
\text { net } \quad 2 \mathrm{H}+\mathrm{C}_{2} \mathrm{H}_{2} & \rightarrow \mathrm{C}_{2} \mathrm{H}_{4} .
\end{aligned}
$$

Thus the model predicted abundance of ethylene is compatible with the infrared observations.

Model runs with different profiles of the eddy mixing coefficient from the standard were done to investigate possible effects on the predicted $\mathrm{C}_{2} \mathrm{H}_{2}$ and $\mathrm{C}_{2} \mathrm{H}_{6}$ abundances. With the value of $K$ held fixed at $10^{6} \mathrm{~cm}^{2}$ $\mathrm{sec}^{-1}$ at the methane homopause, cases with $K$ held constant, varying as $M^{-0.7}$ and $M^{-0.6}$ (where $M$ is the atmospheric number density), were computed to compare to the standard model ( $K$ proportional to $M^{-0.5}$ ). The constant $K$ case produced $\mathrm{C}_{2} \mathrm{H}_{6}$ and $\mathrm{C}_{2} \mathrm{H}_{2}$ abundances identical to the -0.5 case. Decreasing the exponent from the standard model's to -0.6 or -0.7 merely decreases the strength of eddy mixing when compared to the standard case. This results in lowered abundances of ethane and acetylene, with the -0.7 case very similar to the case with $K$ proportional to $M^{-0.5}$ and equal to $10^{5}$ at the methane homopause. Presently there are not enough observations to constrain both the value of $K$ at the methane homopause and its profile.

Recently Caldwell et al. (1987) have used IUE observations of Neptune to infer a $\mathrm{C}_{2} \mathrm{H}_{2}$ mixing ratio of $4 \times 10^{-9}$. This is substantially lower than the value of Orton et 
al. (1987), but in relative agreement with Macy (1980), who from analysis of the 11.5to $13.5-\mu \mathrm{m}$ spectrum of Neptune deduced a mixing ratio of $(0.2-5) \times 10^{-8}$ (note that Macy (1980) and Orton et al. (1987) agree well for ethane, and the data of Orton $e t$ al. (1987) are of higher quality). It is difficult to reconcile these two measurements of $\mathrm{C}_{2} \mathrm{H}_{2}$ unless there are unusual temporal/spatial variations in the stratosphere of Neptune. Another possibility is that the emission at $14 \mu \mathrm{m}$ is not due to $\mathrm{C}_{2} \mathrm{H}_{2}$. However, as discussed above, the inferred acetylene and ethylene abundances of Orton et al. (1987) support each other. Moreover, unless there is unexpected chemistry for acetylene that operates on Neptune, but not on the other Jovian planets, it is hard to produce photochemically the low amount of acetylene that Caldwell et al. call for, because of the large abundance of methane in stratosphere of Neptune.

Last, Lellouch et al. (1986), from the observations of a central flash produced during a stellar occultation by Neptune, deduced a methane abundance of $4-8 \times 10^{-3}$ at approximately the 0.3 -mbar level. This would favor an eddy mixing coefficient closer to $10^{5}$ (see Fig. 4) than the nominal $10^{6}$ adopted here. But, their upper and lower limits are respectively $4 \times 10^{-2}$ and 1 $\times 10^{-4}$, which span the complete range of methane mixing ratios. An alternate interpretation of the data (Hubbard et al. 1987) requires no methane but a gradient in the temperature in the stratosphere from $150^{\circ} \mathrm{K}$ at $1 \mu$ bar to $135^{\circ} \mathrm{K}$ at 0.4 mbar. These temperatures are in agreement with IR data (Orton et al. 1987) and radiative transfer modeling (Appleby 1986). However, the IR observations and radiative transfer modeling require the above-mentioned supersaturation of methane. So this provides an uncertain constraint on the eddy mixing coefficient and methane abundance.

\section{B. Variation with Latitude and}

\section{Photochemical Processes}

The ethane and acetylene mixing ratio profiles corresponding to the different planetary latitudes listed in Table $I$ and for the nominal value of $K$ of $10^{6}$ are shown in Figs. 8 and 9 , respectively. The maximum abun-

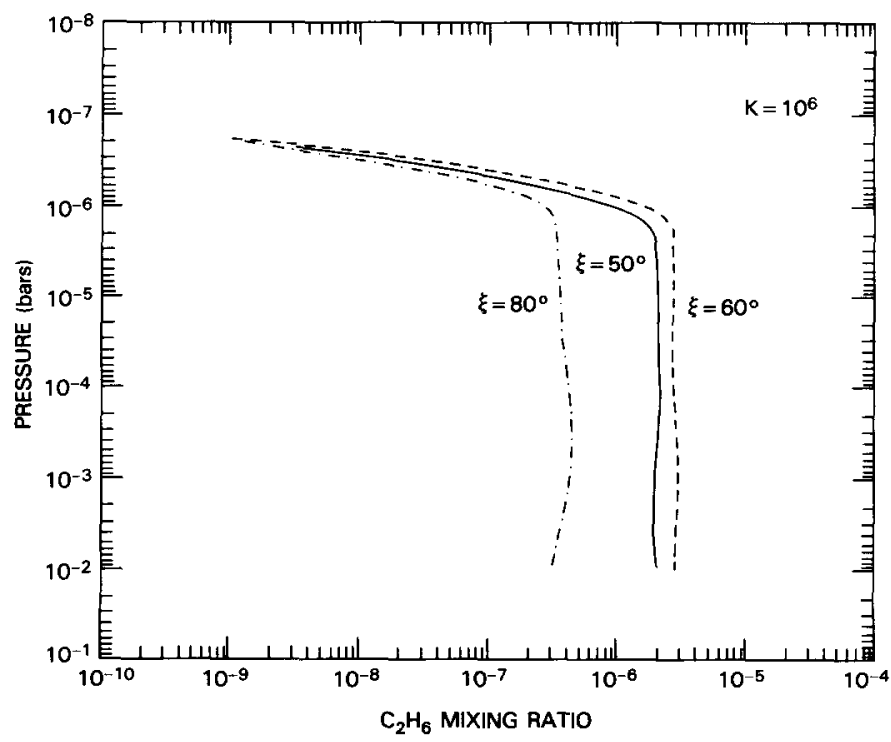

FIG. 8. The mixing ratio of ethane as a function of latitude on Neptune for $K=10^{6} \mathrm{~cm}^{2} \mathrm{sec}^{-1}$. The correspondence of solar zenith angle, $\xi$, to latitude is listed in Table I. 


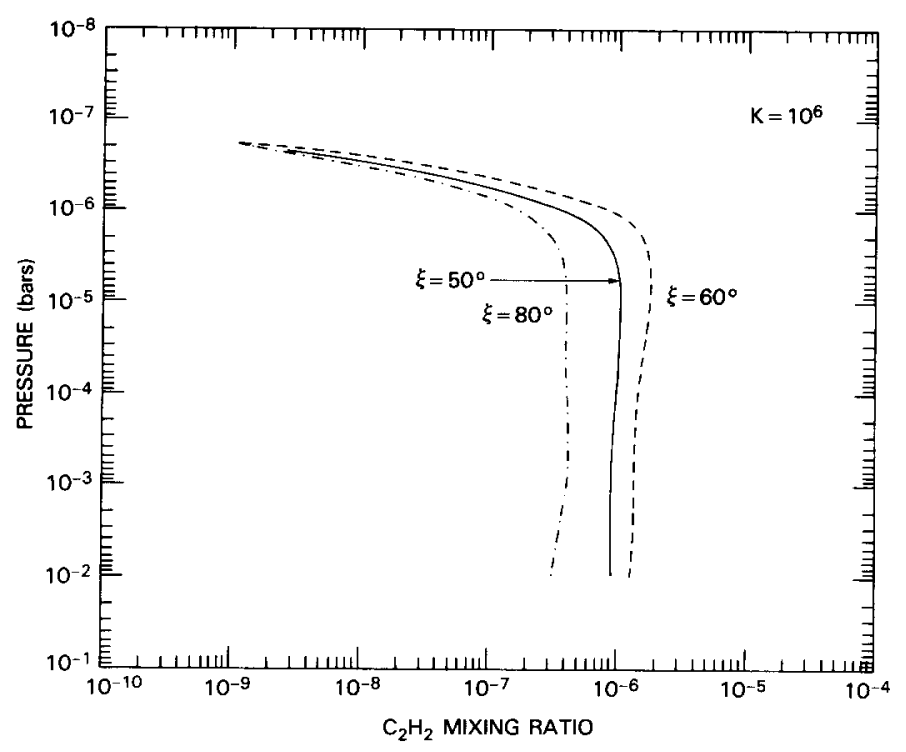

FIG. 9. Same as Fig. 8, but for acetylene.

dances for both species occur at the southernmost latitude (solar zenith angle $60^{\circ}$ ) because of the continuous solar illumination. Note that since our model is 1-d the effects of horizontal mixing are not included. This will act to lessen the latitudinal gradient in mixing ratios that the variation in solar illumination will produce. The corresponding methane mixing ratio profiles are not shown. They exhibit no variation because eddy mixing and molecular diffusion exclusively control the $\mathrm{CH}_{4}$ profile.

The general shape of the mixing ratio curves of acetylene and ethane is easily described. At each latitude, the peak mixing ratios of $\mathrm{C}_{2} \mathrm{H}_{2}$ and $\mathrm{C}_{2} \mathrm{H}_{6}$ occur where $\tau=1$ is reached in Lyman- $\alpha$ due to methane absorption. The peak in mixing ratios shows the expected variation with solar zenith angle, moving to lower pressures for longer slant paths. Because of the large abundance of methane, the maximum abundances occur within two scale heights of the $\mathrm{CH}_{4}$ homopause. Thus, above their maxima the mixing ratios of acetylene and ethane decrease rapidly in abundance due to the decrease in production from methane photolysis and the onset of molecular diffu- sion. Below the maxima mixing ratios the relative abundances of both hydrocarbons are nearly constant, owing to the strong control by eddy mixing over both species. The small "wiggles" seen in the profiles are within the convergence criteria of the model. The details of the production and loss follow.

On Neptune, the abundance of acetylene and ethane is controlled by the production from the direct photolysis of methane. When methane is photolyzed, $90 \%$ of the time the $\mathrm{CH}_{2}$ radical is produced. The other $10 \%$ of the time the $\mathrm{CH}$ radical is produced which reacts primarily with $\mathrm{CH}_{4}$ to produce $\mathrm{C}_{2} \mathrm{H}_{4}$. The methyl radical is produced from both ${ }^{3} \mathrm{CH}_{2}$ and ${ }^{1} \mathrm{CH}_{2}$ and either recycles methane, via the three body reaction with $\mathrm{H}$, or produces ethane, by reacting with itself. But, a significant fraction of the ${ }^{3} \mathrm{CH}_{2}$ reacts with the $\mathrm{CH}_{3}$ to form ethylene. This is because the chemical pathways to form $\mathrm{CH}_{3}$ from ${ }^{3} \mathrm{CH}_{2}$ involve three-body reactions, which are hindered by low number density where methane is undergoing photolysis. This high production rate for $\mathrm{C}_{2} \mathrm{H}_{4}$ produces the large maximum at $1 \mu$ bar seen in Fig. 7. On Neptune approximately $61 \%$ 
of the photons methane absorbs recycle methane, $17 \%$ produce ethylene, and $22 \%$ produce ethane. For comparison, these ratios for Jupiter are $70 \%$ recycle, $10 \%$ to ethylene, and $20 \%$ to ethane (Gladstone 1982). Acetylene is then produced from ethane and ethylene photolysis, with ethylene photolysis being more important.

Below this peak produced by methane photochemistry, the chemical lifetimes become long and eddy mixing controls the profiles of both species. The production of ethane and acetylene declines rapidly below where $\tau=1$ in Lyman- $\alpha$. Ethane is lost by photolysis, but $\mathrm{C}_{2} \mathrm{H}_{6}$ is well shielded by the methane so its destruction is negligible. Acetylene can also be destroyed by photolysis, but its loss is hampered by its low quantum yield for dissociation, recycling of the $\mathrm{C}_{2} \mathrm{H}$ radical by the other hydrocarbons and $\mathrm{H}_{2}$, and the greatly reduced solar flux at Neptune. The ratio of acetylene loss to recycling after it undergoes photolysis is approximately 25 to 1 . This results in the eddy mixing time being 100 times faster than the photochemical loss.

Possible effects of the boundary conditions on the profiles need to be assessed. In Figs. 8 and 9 it can be seen that the upper boundary values of $\mathrm{C}_{2} \mathrm{H}_{2}$ and $\mathrm{C}_{2} \mathrm{H}_{6}$ were held constant for all three latitudes. Properly, they should all be different and reflect diffusive equilibrium. But after a scale height they all have separated showing the limiting influence of an incorrect boundary value. Practically, the strong gradient in mixing ratio from molecular diffusion and the decrease in production results in very little of either of these hydrocarbons above $10^{-6}$ bar. (Molecular diffusion alone will produce a scale height on the order of 5 $\mathrm{km}$.) The analysis of the lifetimes showed that the lower boundary for both species is controlled by eddy diffusion. This will produce a mixing ratio nearly constant with height and was taken into account in setting the lower boundary values. It is also important to realize that just below the lower boundary in the photochemical model acetylene and ethane will freeze out to their ices producing an abrupt decrease in the vapor phase mixing ratios. The vapor abundances from the equilibrium saturation vapor pressure equations will then be the controlling factors.

\section{Variation with Solar Flux}

The two observations of Orton et al. $(1983,1987)$ actually correspond to just past solar maximum and solar minimum conditions, while the acetylene and ethane profiles in Figs. 5 and 6 are for solar maximum conditions. In Figs. 10 and 11 the mixing ratios of acetylene and ethane at solar maximum are compared to their solar minimum values. Decreasing the solar flux from maximum to minimum reduces the mixing ratios by half. This is caused by the halving of the solar Lyman- $\alpha$ flux which halves their production rate from methane photolysis. While this difference is at the limit of our model accuracy the trend is real. The $\mathrm{C}_{2} \mathrm{H}_{2}$ and $\mathrm{C}_{2} \mathrm{H}_{6}$ mixing ratios are a balance between production from photolysis and removal by eddy mixing. So the changing solar UV flux produces a corresponding change in their abundances.

The infrared observations are most sensitive to the abundances in the lower stratosphere. There eddy mixing controls both profiles and has a time constant on the order of 50 years at 1 mbar, while the solar cycle is approximately 11 years. The predicted average mixing ratios of $\mathrm{C}_{2} \mathrm{H}_{6}$ and $\mathrm{C}_{2} \mathrm{H}_{2}$ on Neptune will then lie between the solar maximum and minimum profiles. It is assumed that the eddy mixing remains unchanged over the solar cycle, which cannot be substantiated readily. At the microbar level, where the Voyager Ultraviolet Spectrometer is sensitive, the chemical and mixing time constants are small enough that solar minimum to solar maximum variations will be important. It is interesting to note that the observed increase in the ethane mixing ratio from 1982 to 1985 by Orton $e t$ al. $(1983,1987)$ could be a seasonal effect. The southern hemisphere of Neptune is approaching summer solstice and the ethane abundance should be increasing in response 


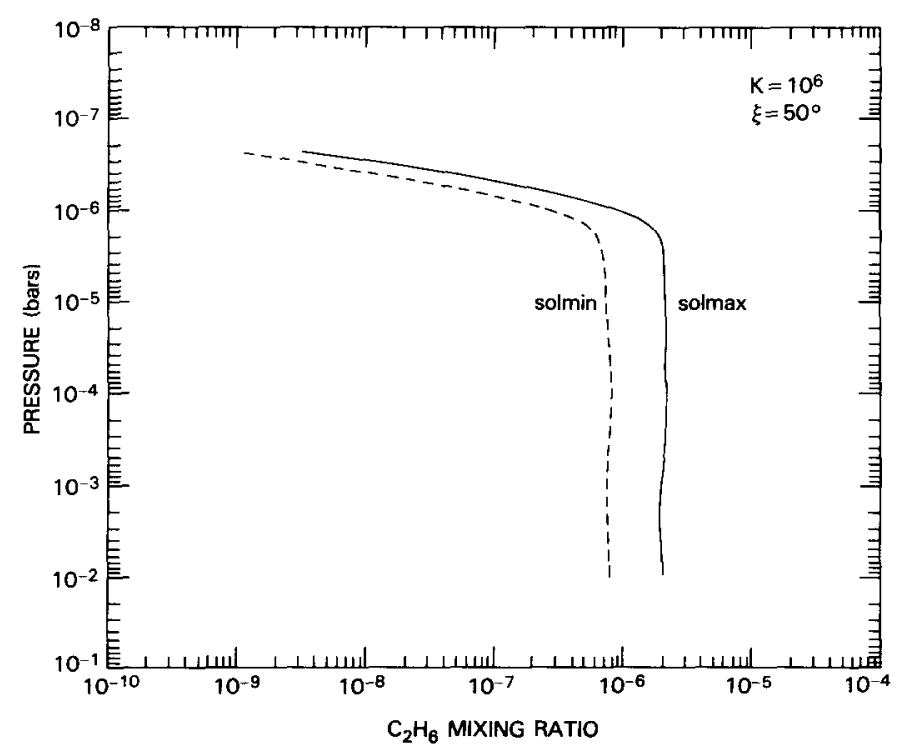

FIG. 10. The mixing ratio profile of ethane as a function of solar activity for $K=10^{6} \mathrm{~cm}^{2} \mathrm{sec}^{-1}$ and a solar zenith angle of $50^{\circ}$.

to the increased solar flux, as was shown in the previous section.

\section{AEROSOL PRODUCTION}

\section{A. Acetylene and Ethane Ice Hazes}

In Fig. 12 the mixing ratios of acetylene and ethane produced by the photochemical model are compared to their relative abundances allowed by their equilibrium saturation vapor pressures over their respective ices (Ziegler 1959, Ziegler et al. 1964). The large differences in abundances between the photochemical model and the equilibrium saturation values makes condensation

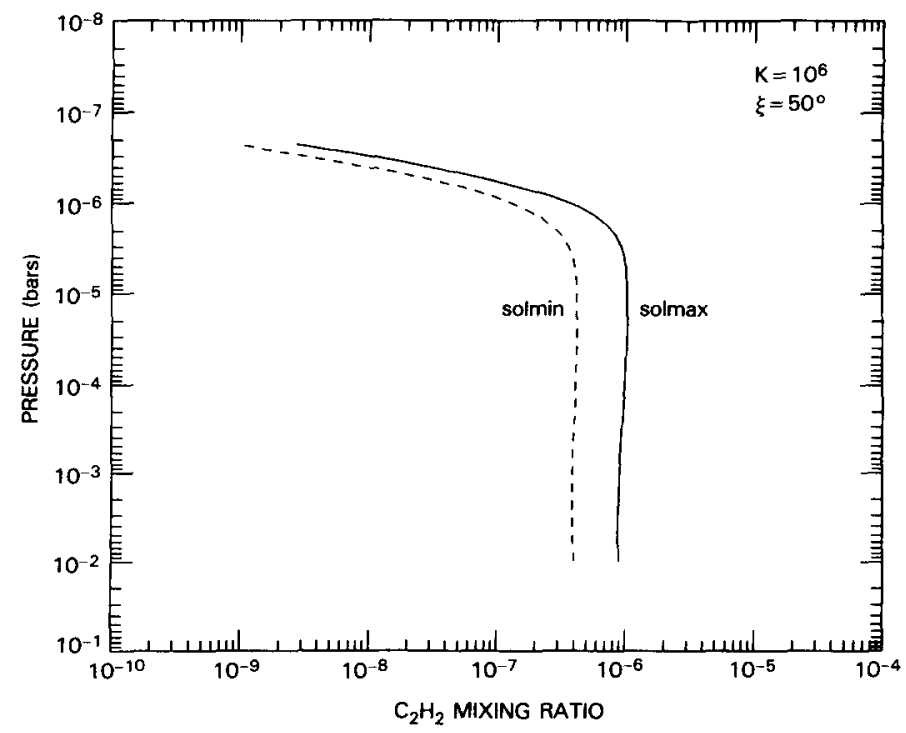

FIG. 11. Same as Fig. 10, but for acetylene. 


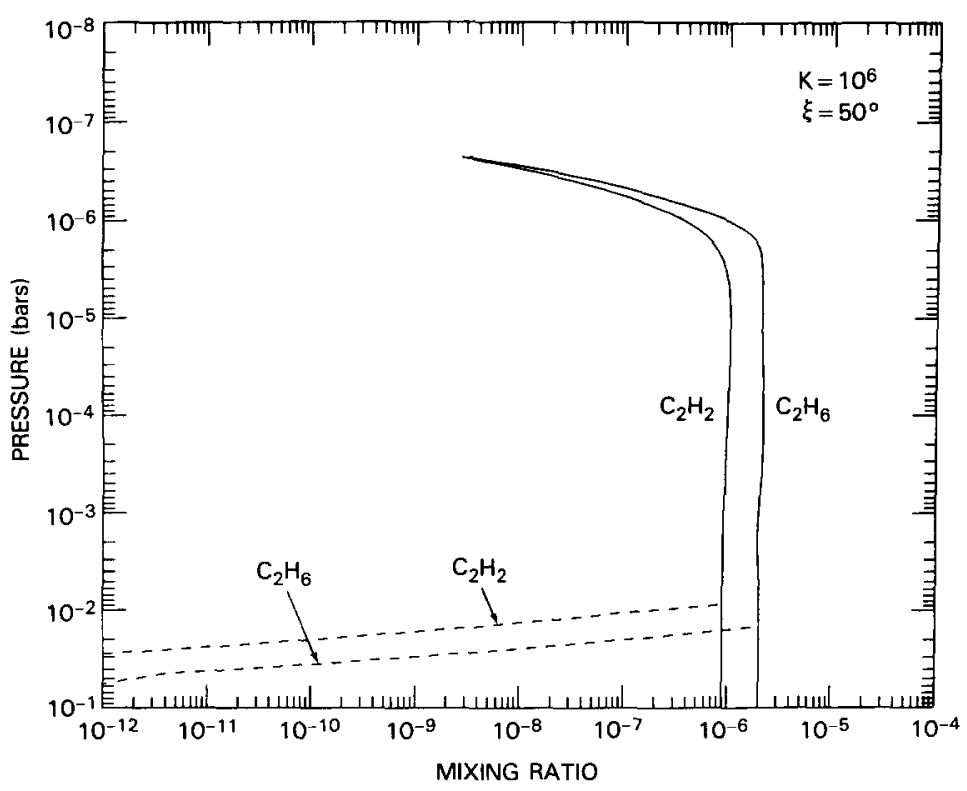

FIG. 12. The mixing ratio profiles of ethane and acetylene produced by the photochemical model for $K=10^{6} \mathrm{~cm}^{2} \mathrm{sec}^{-1}$ and a solar zenith angle of $50^{\circ}$ (solid lines) compared to the maximum vapor phase abundances from their equilibrium saturation vapor pressures over their respective ices (dashed lines). Where the lines for a given species cross, condensation is expected to occur.

of these hydrocarbons to their ices near the tropopause a certainty. The expected levels of condensation ( $100 \%$ saturation level) are listed in Table III. As the vapor pressures change by an order of magnitude for a change in temperature of $5^{\circ} \mathrm{K}$, the location of these levels is strongly controlled by the local temperature. When comparing these

TABLE III

Condensation Levels and Column Densities of HYDROCARBON ICES

\begin{tabular}{lccc}
\hline Species & $\begin{array}{c}T \\
(\mathrm{~K})\end{array}$ & $\begin{array}{c}P \\
(\mathrm{mbar})\end{array}$ & $\begin{array}{c}\text { Column density } \\
\left(\mathrm{g} \mathrm{cm}^{-2}\right)\end{array}$ \\
\hline $\mathrm{C}_{4} \mathrm{H}_{2}{ }^{b}$ & 104 & 3.5 & $7 \times 10^{-6}$ \\
$\mathrm{C}_{2} \mathrm{H}_{2}$ & 83 & 9.0 & $9 \times 10^{-5}$ \\
$\mathrm{C}_{2} \mathrm{H}_{6}$ & 74 & 15.0 & $4 \times 10^{-4}$ \\
\hline
\end{tabular}

\footnotetext{
a Column densities were calculated assuming no loss by sedimentation.

${ }^{b}$ Recent preliminary vapor pressure measurements of Hudson et al. (1987) would raise the diacetylene condensation level to $117^{\circ} \mathrm{K}$ and 2 mbar.
}

predicted levels to other models of the thermal structure of the lower stratosphere of Neptune, the corresponding temperatures should be used to determine the levels of condensation, not the pressure or altitude levels.

Ethylene ice might also be expected to form as the maximum mixing ratio of $\mathrm{C}_{2} \mathrm{H}_{4}$ at the tropopause allowed by its equilibrium saturation vapor pressure over its ice is $5 \times$ $10^{-13}$, much less than the $2 \times 10^{-9}$ predicted from photochemistry in the lower stratosphere. As mentioned previously the ethylene abundance depends upon production from vapor phase $\mathrm{C}_{2} \mathrm{H}_{2}$. Acetylene condensation takes place at lower pressure (warmer temperature) than would ethylene condensation. This removal of $\mathrm{C}_{2} \mathrm{H}_{2}$ from the vapor phase causes the $\mathrm{C}_{2} \mathrm{H}_{4}$ abundance to drop below the saturation limited level. So unless there is substantial supersaturation of acetylene no ethylene condensation occurs.

All of the vapor pressure equations used 
in this section are listed in Appendix A. We stress the need for better vapor pressure measurements of acetylene and diacetylene. We are currently forced to extrapolate these vapor pressures below the temperatures at which they have been measured. The bias in this extrapolation is to predict larger vapor pressures than the actual ones and to move the predicted condensation levels to higher pressures.

To determine the effect these ice hazes could have on the scattering properties of the stratosphere of Neptune in the visible, we calculated the haze optical depths. The optical depth is the product of the particle column density and scattering cross section. We first calculated column densities of the ice hazes with no removal of the particles by sedimentation to determine the greatest possible effect. We converted the mass densities of Table III into particle densities for $0.1-, 1.0-$, and 10.0 - $\mu \mathrm{m}$-radius spheres. This was to span the range of particle sizes found for stratospheric hazes (West et al. 1986, Pollack et al. 1987). To calculate the scattering cross sections it is necessary to know the indices of refraction of these ices, but a literature search revealed no direct measurements. The real parts of the indices of refraction for acetylene and ethane ice were then computed from the molar refractivity data of Vogel (1948) and densities listed in the Crystal Data Determinative Tables (Donnay and Ondik 1972). We assumed that the imaginary index of refraction was negligible. In the gas phase $\mathrm{C}_{2} \mathrm{H}_{2}$ and $\mathrm{C}_{2} \mathrm{H}_{6}$ have no absorption in the visible, and it is unlikely that by condensing to their ices they will develop significant absorption. But if scattering becomes appreciable, minor absorption may become important because of the long optical paths of the scattered light. The scattering cross sections were then calculated by a Mie-scattering code, and the optical depths resulting from this calculation are given in Table IV.

Constraints on the total stratospheric aerosol optical depth come from observa-
TABLE IV

Maximum Possible Hydrocarbon Ice Haze Optical Depths as a Function of Wavelength and Particle Size

\begin{tabular}{cccc}
\hline $\begin{array}{c}\text { Particle radius } \\
(\mu \mathrm{m})\end{array}$ & \multicolumn{3}{c}{$\begin{array}{c}\text { Wavelength } \\
(\mu \mathrm{m})\end{array}$} \\
\cline { 2 - 4 } & 0.3 & 0.4 & 0.5 \\
\hline \multicolumn{4}{c}{ Ethane ice } \\
0.1 & 70.0 & 29.0 & 15.0 \\
1.0 & 9.2 & 8.4 & 13.0 \\
10.0 & 0.86 & 0.87 & 0.93 \\
& Acetylene ice & \\
0.1 & 8.2 & 3.5 & 1.9 \\
1.0 & 1.7 & 2.7 & 1.8 \\
10.0 & 0.2 & 0.2 & 0.2 \\
\hline
\end{tabular}

tions in the UV to the near IR (Savage et al. 1980, Caldwell et al. 1981, Bergstralh and Baines 1984, Bergstralh et al. 1987, Baines et al. 1987). From the UV albedo of Neptune Savage et al. (1980) deduced the presence of stratospheric aerosols. Caldwell et al. (1981) argued that no aerosol opacity is possible because of the difficulties in selecting the proper solar analog star to determine the albedos. The clearest evidence for stratospheric aerosols comes from the observations done in the near IR and visible wavelengths (Bergstralh et al. 1987). The $0.9-\mu \mathrm{m}$ methane band of Neptune has a residual intensity of $1 \%$. It would have a residual intensity of $0.1 \%$ if not for the presence of aerosols. Bergstralh et al. (1987) deduce an optical depth of 0.1 to 0.25 at 0.9 $\mu \mathrm{m}$ depending on the pressure level of the hazes (1-20 mbar). A total optical depth of 0.5 in the visible (upper troposphere and stratospheric aerosols) for Neptune has been derived by Baines et al. (1987).

As can be seen from Tables III and IV the acetylene and ethane ice hazes can provide more than enough optical depth at the appropriate pressure levels. Another possible source of stratospheric aerosols is methane ice crystals being transported from the tropopause into the stratosphere. However, the sublimating methane ice crystals will 
TABLE V

\begin{tabular}{|c|c|c|c|}
\hline $\begin{array}{r}\text { Optical Dept } \\
\text { WITH SeDI } \\
\text { WaVEl }\end{array}$ & $\begin{array}{l}\text { DROC } \\
\text { N AS A } \\
\text { D PAR }\end{array}$ & $\begin{array}{l}\text { N IC } \\
\text { NCTI } \\
\text { E Si }\end{array}$ & \\
\hline $\begin{array}{l}\text { Particle radius } \\
\qquad(\mu \mathrm{m})\end{array}$ & & $\begin{array}{l}\text { ivelen } \\
(\mu \mathrm{m})\end{array}$ & \\
\hline & 0.3 & 0.4 & 0.5 \\
\hline & he ice & & \\
\hline 0.1 & 70.0 & 29.0 & 15.0 \\
\hline 1.0 & 0.9 & 0.8 & 1.3 \\
\hline 10.0 & 0.0 & 0.0 & 0.0 \\
\hline & ene ice & & \\
\hline 0.1 & 8.2 & 3.5 & 1.9 \\
\hline 1.0 & 0.2 & 0.3 & 0.2 \\
\hline 10.0 & 0.0 & 0.0 & 0.0 \\
\hline
\end{tabular}

produce the observed $2 \%$ vapor phase mixing ratio at 26 mbar $\left(\approx 64^{\circ} \mathrm{K}\right.$, and $25 \mathrm{~km}$; Kirk and Zeigler 1965), so we do not expect them to survive to much lower pressures.

That the observed optical depths are much less than the maximum optical depths calculated here is not surprising. We expect the optical depths of the $\mathrm{C}_{2} \mathrm{H}_{2}$ and $\mathrm{C}_{2} \mathrm{H}_{6}$ ice hazes to be reduced by sedimentation and other cloud microphysics effects. To incorporate sedimentation into the model we performed the following analysis. The source of the hazes is the eddy mixing of $\mathrm{C}_{2} \mathrm{H}_{2}$ and $\mathrm{C}_{2} \mathrm{H}_{6}$ in the gas phase into the condensation region, while the sink is the sedimentation of the ice particles. In steady state the two fluxes must balance each other or

$$
K * N * d f_{i} / d z=n / t,
$$

where $N$ is the atmospheric number density, $f_{i}$ the vapor phase mixing ratio of either acetylene or ethane (constrained to follow the saturation curve), $n$ the column density of either acetylene or ethane in the condensed phase, and $t$ the sedimentation time for the aerosols to fall from the condensation level. The above equation was solved for $n$ and the corresponding optical depths are given in Table $\mathrm{V}$.

From Table $V$ we can see that the 0.1$\mu \mathrm{m}$-radius particles fall too slowly to re- duce their optical depths from the maximal ones. If we constrain the total optical depth to the limits set by Bergstralh et al. (1987) and Baines et al. (1987) then the ice haze particles must be on the order of $1.0 \mu \mathrm{m}$ in radius. This is surprising as the size of atmospheric aerosols is usually on the order of $0.1 \mu \mathrm{m}$ in radius. A major uncertainty in this calculation is the strength of the eddy mixing at the condensation levels. Currently this is not well constrained, and if it is lower than our assumed value then the ice haze particle radius will drop.

\section{B. Polyacetylenes}

The other aerosols that can be produced from methane photochemistry are polyacetylenes $\left(\mathrm{C}_{2 n} \mathrm{H}_{2}, n=2,3, \ldots\right)$. Polyacetylenes can produce absorption in the visible and have been proposed as a mechanism for producing the observed darkening of Titan with increasing solar activity (Allen et al. 1980). The albedo of Neptune has also been observed to change with solar activity (Lockwood and Thompson 1979,1986$)$. The mixing ratio profile of $\mathrm{C}_{4} \mathrm{H}_{2}$ calculated by the methane photolysis model as a function of solar activity, along with its mixing ratio from its vapor pressure over the ice, are shown in Fig. 13. The optical depth of the diacetylene ice haze was not included in the previous discussion as its density is an order of magnitude lower than the acetylene and ethane ice hazes.

At pressures lower than about $2 \times 10^{-4}$ bar $\mathrm{C}_{4} \mathrm{H}_{2}$ is in photochemical equilibrium with production balanced by loss at each level. At higher pressures the production rate increases, and the loss becomes a mix of photochemistry and eddy diffusion. The mixing ratio of diacetylene increases near the tropopause because of the increasing optical depth of acetylene and less efficient recycling of the $\mathrm{C}_{2} \mathrm{H}$ radical back to acetylene. The reaction which produces $\mathrm{C}_{4} \mathrm{H}_{2}$,

$$
\mathrm{C}_{2} \mathrm{H}+\mathrm{C}_{2} \mathrm{H}_{2} \rightarrow \mathrm{C}_{4} \mathrm{H}_{2}+\mathrm{H},
$$

has little if any energy barrier and thus is independent of temperature, while the reac- 


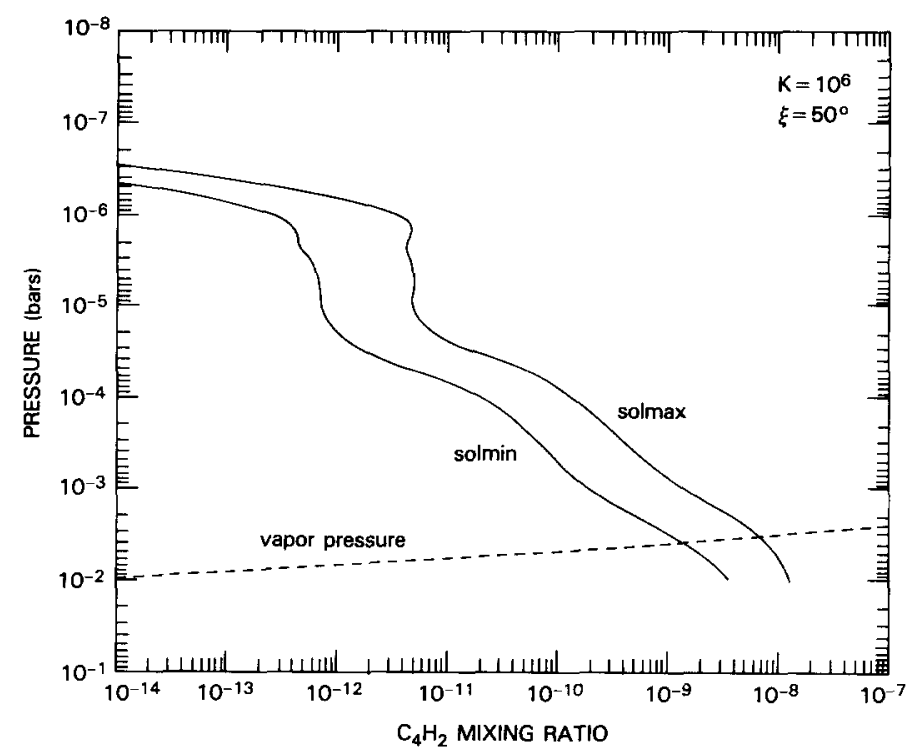

FIG. 13. The mixing ratio profile of diacetylene produced by the photochemical model for $K=10^{6}$ $\mathrm{cm}^{2} \mathrm{sec}^{-1}$ and a solar zenith angle of $50^{\circ}$ as a function of solar activity (solid lines) compared to the maximum vapor phase abundance from its equilibrium saturation vapor pressure over its ice (dashed lines). Where the saturation vapor abundance becomes less than a photochemical model abundance, condensation is expected to occur.

tions of $\mathrm{C}_{2} \mathrm{H}$ with $\mathrm{H}_{2}, \mathrm{CH}_{4}$, and $\mathrm{C}_{2} \mathrm{H}_{6}$ have an energy barrier (Laufer 1982). As the temperature decreases near the tropopause the recycling reactions give way to the production of the polyacetylenes, but condensation will also occur.

This competition between the production of higher order polyacetylenes by photochemistry and isolation by condensation on Neptune also takes place on Uranus (Romani and Atreya 1986). Uranus stratospheric aerosols are also most likely dominated by hydrocarbon ices and polyacetylenes (Pollack et al. 1987). Comparisons between the single-scattering albedo of the stratospheric aerosols on Uranus and Neptune (Bergstralh and Baines 1984, Bergstralh et al. 1987) show the Neptune aerosols to be brighter. This is consistent with predictions from the combined photochemistry and condensation modeling. On Neptune, at the condensation level of diacetylene, the combined column production rate of $\mathrm{C}_{6} \mathrm{H}_{2}$ and $\mathrm{C}_{8} \mathrm{H}_{2}$ is $2 \times 10^{4}$ mole- cules $\mathrm{cm}^{-2} \mathrm{sec}^{-1}$; for Uranus the corresponding rate is $5 \times 10^{5}$. The low abundance of hydrocarbons on Uranus, caused by methane in the stratosphere being saturation-limited at the tropopause, limits the recycling of acetylene and diacetylene after they undergo photolysis. For acetylene, the ratio of recycling to polyacetylene production upon undergoing photolysis is approximately 25 to 1 on Neptune and 3 to 1 on Uranus. For diacetylene, the same ratios are 74 to 1 for Neptune and nearly 1 to 1 for Uranus.

Another possible source of visible absorbing aerosols for Uranus and Neptune is the irradiation of acetylene ice and subsequent production of polymers. Stief et al. (1964) observed hydrogen production from UV irradiation of $\mathrm{C}_{2} \mathrm{H}_{2}$ ice, and a waxy substance was left behind after the ice was allowed to sublimate (L. J. Stief, personal communication 1987). On Neptune this will be reduced by the relatively large abundance of gaseous acetylene above the ice 
which will shield it from the UV, and the active dynamics observed in the lower stratosphere which will remove the ice particles before radiation can postprocess them. On Uranus, irradiation processing of the ice will be more likely as the acetylene is optically thin above the ice layer, and the stratosphere appears to be very quiescent.

Irradiation of the ice by charged particles also appears more likely on Uranus than on Neptune. On Uranus, the charged particle flux arises from its magnetosphere and perhaps from electroglow electrons. The relatively low value of Lyman- $\alpha$ on Neptune (IUE measurements of $\leq 200 \mathrm{R}, \mathrm{J}$. T. Clarke, personal communication 1986, 1987) indicates a smaller electroglow component on Neptune than on Uranus, but it does not necessarily rule out a modest magnetospheric environment around Neptune (Atreya 1986).

Whether the observed $4 \%$ change in the visible albedo of Neptune (Lockwood and Thompson 1986) is caused by the change in the rate of polyacetylene production is not certain. As can be seen in Fig. 13, the diacetylene mixing ratio at its condensation level approximately triples going from solar minimum to maximum. A similar increase is seen in the production rates of the polyacetylenes $\mathrm{C}_{6} \mathrm{H}_{2}$ and $\mathrm{C}_{8} \mathrm{H}_{2}$. However, the albedo data show the nearly zero phase lag with solar UV activity. While the lifetime of diacetylene is less than the solar cycle above 0.2 mbar, the production lifetime at its peak is 32 years, longer than the solar cycle. Simple linear theory predicts a $90^{\circ}$ phase lag in the peak of diacetylene production from the time of peak solar activity and a decrease in the amplitude of the change for this difference in time scales. Thus it is not evident that the polyacetylene production can supply the observed albedo change and more work is needed to test the mechanism. The photochemistry model can be coupled to both a cloud microphysics model and a radiative transfer model to determine the extent to which changes in the gas production of the polyacetylenes change the albedo. The albedo data need to be analyzed for possible latitudinal and seasonal components as the long photochemical production lifetime of the polyacetylenes indicates that dynamical processes will be important for their global distribution. Methane photochemistry may still provide the source for the albedo change via irradiation of the hydrocarbon ices or through another chemical pathway.

\section{SUMMARY}

On Neptune, the large abundance of stratospheric methane $(\approx 2 \%)$ forces photolysis to occur near the homopause where gravitational separation clears the atmosphere. A nominal eddy mixing coefficient of $10^{6} \mathrm{~cm}^{2} \mathrm{sec}^{-1}$ at the methane homopause and proportional to the inverse square root of the atmospheric number density was selected based on observations of Neptune and comparisons to the other Jovian planets. For methane, eddy mixing and molecular diffusion lifetimes are always shorter than photochemical lifetimes. The predicted global average mixing ratios of $\mathrm{C}_{2} \mathrm{H}_{6}$ and $\mathrm{C}_{2} \mathrm{H}_{2}, 1.5 \times 10^{-6}$ and $6 \times 10^{-7}$, respectively, agree reasonably with the abundances deduced by measurements in the IR (Orton et al. 1987). The peak abundances of both acetylene and ethane occur at the level where maximum production from methane photolysis occurs, the level where an optical depth of one is reached in Lyman- $\alpha$. Above this level they rapidly decrease with altitude due to molecular diffusion and the fall off of production from methane photolysis. Below, their mixing ratios are nearly constant with height due to dominance of eddy mixing. Loss of ethane and acetylene by photolysis is inefficient. For ethane, photolysis is hindered by shielding from methane; for acetylene, it is hindered by efficient recycling of its photolysis products by the other hydrocarbons, its low quantum efficiency for dissociation, and the greatly reduced solar flux at Neptune. The detection of ethane on Neptune, but not on Uranus, is due to both the larger 
abundance of ethane and a warmer lower stratosphere on Neptune compared to Uranus. The greater ethane abundance on Neptune is a direct consequence of the larger abundance of stratospheric methane available for photolysis.

Methane photochemistry produces aerosols in the form of hydrocarbon ices and polyacetylenes in the stratosphere of Neptune. Ethane, acetylene, and diacetylene are produced in large enough abundances from methane photolysis to condense to their respective ices near the tropopause. The predicted levels of these ice hazes agree well with observations of Neptune in the near IR and visible which require stratospheric aerosols in the same region (Bergstralh et al. 1987, Baines et al. 1987). These ice hazes are also capable of providing the observed stratospheric aerosol optical depth. Comparisons of model predictions were made to Uranus, the only other planet where the stratospheric aerosols are liable to be primarily from methane photochemistry producing hydrocarbon ices and polyacetylenes. (On Titan, the other planetary body where the production of aerosols from $\mathrm{CH}_{4}$ photolysis is significant, the presence of nitrogen complicates the process (Sagan and Thompson 1984). Also the warmer temperatures allow for liquid clouds to form. This makes Titan not directly comparable to Uranus or Neptune.) We predict a lower ratio of polyacetylene production to ice and a lower probability of UV postprocessing of the acetylene ice to polymers on Neptune compared to Uranus. The single-scattering albedo of the stratospheric aerosols in the visible is greater on Neptune than on Uranus (Bergstralh et al. 1987, Bergstralh and Baines 1984). This is agreement with the above predictions as the hydrocarbon ices are brighter than polyacetylenes.

Future work will consist of better incorporating condensation into the photochemical model and adding more cloud microphysical processes. This will improve the mixing ratios of the condensables in the lower stratosphere and the calculated ice haze properties.

We look forward to the upcoming Voyager 2 encounter with Neptune in August 1989. The predicted abundances of $\mathrm{C}_{2} \mathrm{H}_{2}$ and $\mathrm{C}_{2} \mathrm{H}_{6}$ coupled with the warm stratosphere may make them detectable by the IRIS. The occultation experiments performed by the Ultraviolet Spectrometer will determine the eddy mixing coefficient, which must still be taken as a free parameter in this model. Observations made by the photopolarimeter (PPS) and imaging instruments (ISS) will also provide further constraints and information about the stratospheric aerosols.

\section{APPENDIX A}

\section{Hydrocarbon Vapor Pressure EQUATIONS}

$\mathrm{Vp}$ is the equilibrium saturation vapor pressure of hydrocarbon over its ice in $\mathrm{mm}$ $\mathrm{Hg}$ except where otherwise noted. $T$ is temperature in degrees Kelvin.

$$
\begin{aligned}
& \text { Methane } \\
& \begin{array}{r}
\log _{10}(\mathrm{Vp}) \\
=4.425070-453.92414 / T-4055.6016 / \\
+115352.19 / T^{3}-1165560.7 / T^{4} \\
35^{\circ} \mathrm{K}<T<90.652^{\circ} \mathrm{K} .
\end{array}
\end{aligned}
$$

$\mathrm{Vp}$ is vapor pressure in atmospheres, from Kirk and Ziegler (1965).

$$
\begin{aligned}
& \text { Ethane } \\
& \qquad \begin{array}{c}
\log _{10}(\mathrm{Vp})=10.01-1085.0 /(T-0.561) \\
40^{\circ} \mathrm{K}<T<89.89^{\circ} \mathrm{K},
\end{array}
\end{aligned}
$$

fit to data given in Ziegler et al. (1964).

Acetylene

$$
\begin{gathered}
\log _{10}(\mathrm{Vp})=9.130-1149.0 /(T-3.840) \\
115^{\circ} \mathrm{K}<T<145^{\circ} \mathrm{K} \\
\log _{10}(\mathrm{Vp})=30.895-8.6252 * \log _{10}(T) \\
\quad-1645.9 / T \\
98^{\circ} \mathrm{K}<T<115^{\circ} \mathrm{K}
\end{gathered}
$$

fit to data given in Zeigler (1959). 
Diacetylene

$$
\begin{gathered}
\ln (\mathrm{Vp})=22.915-4369.4 / T \\
190^{\circ} \mathrm{K}<T<232^{\circ} \mathrm{K}
\end{gathered}
$$

fit to data given in Stull (1947).

\section{ACKNOWLEDGMENTS}

P. N. Romani acknowledges the National Science Foundation Graduate Fellowship Program and the NASA Planetary Atmospheres Program under Grant NSG-7404 for support during graduate school, and the NAS/NRC Resident Research program for support at NASA/GSFC. S. K. Atreya acknowledges support received from NASA Grant NSG-7404 and the Voyager project. We have benefited from discussions with $\mathrm{V}$. Kunde, L. Stief, and M. Flassar and from helpful comments from our referees.

\section{REFERENCES}

Allen, M., J. P. Pinto, And Y. L. Yung 1980. Titan aerosol photochemistry and variations related to the sunspot cycle. Astrophys. J. 242, L125-L128.

Ames, W. F. 1969. Numerical Methods for Partial Differential Equations. Barnes and Noble, New York.

ApPleby, J. F. 1986. Radiative-convective equilibrium models of Uranus and Neptune. Icarus $\mathbf{6 5}$, 383-405.

AtreyA, S. K. 1982. Eddy mixing coefficient on Saturn. Planet. Space Sci. 30, 849-854.

ATREYA, S. K. 1986. Atmospheres and Ionospheres of the Outer Planets and Their Satellites. SpringerVerlag, New York.

Atreya, S. K., T. M. Donahue, and M. C. Festou 1981. Jupiter: Structure and composition of the upper atmosphere. Astrophys. J. 247, L43-L47.

Atreya, S. K., And J. J. Ponthieu 1983. Photolysis of methane and the ionosphere of Uranus. Planet. Space Sci. 31, 939-944.

Atreya, S. K., And P. N. Romani 1985. Photochemistry and clouds of Jupiter, Saturn, and Uranus. In Recent Advances in Planetary Meterology (G. E. Hint, Ed.), pp. 17-68. Cambridge University Press, Cambridge.

Atreya, S. K., P. N. Romani, B. R. Sandel, F. Herbert, A. L. Broadfoot, and R. Yelle 1986. Voyager/Uranus UV occultations-Atmospheric vertical mixing and photochemistry. Bull. Amer. Astron. Soc. 18, 758.

Atreya, S. K., J. H. Waite, T. M. Donahue, A. F. NAGY, AND J. C. McConnell 1984. Theory, measurements and models of the upper atmosphere and ionosphere of Saturn. In Saturn (T. Gehrels, Ed.), pp. 239-277. Univ. of Arizona Press, Tucson.

Baines, K. H., J. T. Bergstralh, R. J. Terrile, D. Wenkert, J. NefF, B. A. SMith, AND W. H. SмIтH 1987. Aerosol and gas distributions in the troposphere of Neptune: Constraints from broadband imagery and low and high-resolution spectrophotometry. Bull. Amer. Astron. Soc. 19, 639.

Bergstralh, J. T., ANd K. H. Baines 1984. Properties of the upper tropospheres of Uranus and Neptune derived from observations at "visible" to nearinfrared wavelengths. In Uranus and Neptune (J. T. Bergstralh, Ed.), pp. 179-212. NASA Conference Publication 2330.

Bergstralh, J. T., K. H. Baines, R. J. Terrile, D. Wenkert, J. NefF, ANd B. A. Smith 1987. Aerosols in the stratosphere of Neptune: Constraints from near-Ir broadband imagery and UV, blue, and near-Ir spectrophotometry. Bull. Amer. Astron. Soc. 19, 639.

Caldwell, J., T. Owen, A. R. Rivolo, V. Moore, G. E. Hunt, AND P. S. Butterworth 1981. Observations of Uranus, Neptune and Titan by the International Ultraviolet Explorer. Astron. J. 86, 298 305.

Caldwell, J., R. Wagener, and K. Fricke 1987. The composition of the stratospheres of Uranus and Neptune. In Program and Abstracts Book of Origin and Evolution of Planetary Satellite Atmospheres Meeting (S. K. Atreya and J. B. Pollack, Eds.), p. 45.

Courtin, R., D. Gautier, and L. Lacombe 1979. Indications of supersaturated stratospheric methane in Neptune from its atmospheric thermal profile. Icarus 37, 236-248.

Donnay, J. D. H., AND H. M. ONdik (Eds.) 1972. Crystal Data Determinative Tables. Organic Compounds 1972, 3rd ed., Vol. I. National Bureau of Standards, Washington, DC.

French, R. G., J. H. Elias, D. J. Mink, and J. L. Elliot 1983. The structure of Neptune's upper at mosphere: The stellar occultation of 24 May 1981. Icarus 55, 332-336.

FritTs, D. C. 1984. Gravity wave saturation in the middle atmosphere: A review of theory and observations. J. Geophys. Res. 22, 275-308.

Gillett, F. C., AND G. H. Rieke 1977. 5-20 micron observations of Uranus and Neptune. Astrophys. $J$. 218, L141-L.144.

Gladstone, G. R. 1982. Radiative Transfer and Photochemistry in the Upper Atmosphere of Jupiter. Ph.D. thesis, California Institute of Technology.

Glicker, S., ANd H. Okabe 1987. Photochemistry of Diacetylene. J. Phys. Chem. 91, 437-440.

Herbert, F., B. R. Sandel, R. V. Yelle, J. B. Holberg, A. L. Broadfoot, D. E. Shemansky, S. K. Atreya, And P. N. Romani 1987. The upper atmosphere of Uranus: EUV occultations observed by Voyager 2. J. Geophys. Res. 92, 15093-15109.

Heroux, L., AND H. E. Hinteregger 1978. Aeronomical reference spectrum for solar UV below $2000 \AA$ A. J. Geophys. Res. 83, 5305-5308.

Hubbard, W. B., P. D. Nicholson, E. Lellouch, B. Sicardy, A. Brahic, F. Villas, P. Bouchet, 
R. A. Mclaren, R. L. Millis, L. H. Wasserman, J. H. Elias, K. Matthews, and C. Perrier 1987. Oblateness, radius, and mean stratospheric temperature of Neptune from the 1985 August 20 occultation. Icarus 72, 635-646.

Hudson, C. M., J. E. Allen, Jr., M. A. PereraJARMER, AND R. K. KHANNA 1987. Laboratory vapor pressure measurements of hydrocarbons and nitriles. In Proceedings of the 2nd Annual Meeting of Laboratory Measurements for Planetary Science, in press.

Joyce, R. R., C. B. Pilcher, D. P. Cruikshank, AND D. MORRISON 1977. Evidence for weather on Neptune I. Astrophys. J. 214, 657-662.

KIRK, B. S., AND W. T. ZIEgler 1965. A phase-equilibrium apparatus for gas-liquid systems and the gas phase of gas-solid systems: Application to methanehydrogen from $66.88^{\circ}$ to $116.53^{\circ} \mathrm{K}$ and up to 125 atmospheres. In Advances in Cryogenic Engineering (K. D. Timmerhaus, Ed.), Vol. 10, Part 2, pp. 160170. Plenum, New York.

LAUFER, A. H. 1982. Kinetics and photochemistry of planetary atmospheres. In Abstracts of the Fourth Annual Meeting of Planetary Atmospheres Principal Investigators (S. K. Atreya and D. Swartz, Eds.), pp. 137-138. University of Michigan Press.

Lellouch, E., W. B. Hubbard, B. Sicardy, F. VILAS, AND P. BOUCHET 1986. Occultation determination of Neptune's oblateness and methane stratospheric mixing ratio. Nature 324, 227-231.

LindzEN, R. S. 1971. Tides and gravity waves in the upper atmosphere. In Mesospheric Models and Related Experiments (G. Fiocco, Ed.), pp. 122-130. Reidel, Dordrecht.

LiNDZEN, R. S. 1981. Turbulence and stress owing to gravity wave and tidal breakdown. J. Geophys. Res. 86, 9707-9714.

Liou, K.-N. 1980. An Introduction to Atmospheric Radiation. Academic Press, New York.

Lockwood, G. W., AND D. T. Thompson 1979. A relationship between solar activity and planetary albedos. Nature 280, 43-45.

Lockwood, G. W., AND D. T. Thompson 1986. Long-term brightness variations of Neptune and the solar cycle modulation of its albedo. Science 234, 1543-1545.

MACY, W., JR. 1980. Mixing ratios of methane, ethane, and acetylene in Neptune's stratosphere. Icarus 41, 153-158.

Macy, W., JR. AND W. Sinton 1977. Detection of methane and ethane in emission on Neptune but not on Uranus. Astrophys. J. 218, L79-L81.

Marrero, T. R., AND E. A. Mason 1972. Gaseous diffusion coefficients. J. Phys. Chem. Ref. Data 1, 3-118.

Mount, G. H., and G. J. RotTman 1981. The solar spectral irradiance 1200-3184 $\AA$ near solar maximum: July 15, 1980. J. Geophys. Res. 86, 91939198.
Orton, G. S., D. K. Aitken, C. Smith, P. F. Rouche, J. Caldwell, and R. SNyder 1987. The spectra of Uranus and Neptune at 8-14 and 17-23 $\mu \mathrm{m}$. Icarus 70, 1-12.

Orton, G. S., AND J. F. Appleby 1984. Temperature structure and infrared-derived properties of the atmospheres of Uranus and Neptune. In Uranus and Neptune (J. T. Bergstralh, Ed.), pp. 89-156. NASA Conference Publication 2330.

Orton, G. S., A. T. Tokunaga, and J. Caldwell 1983. Observational constraints on the atmospheres of Uranus and Neptune from new measurements near $10 \mu \mathrm{m}$. Icarus 56, 147-164.

Pearl, J. C., B. J. Conrath, R. A. Hannel, J. A. Pirraglia, And A. Coustenis 1987. Energy balance of Uranus: Preliminary Voyager results. Bull. Amer. Astron. Soc. 19, 852.

Pilcher, C. B. 1977. Evidence for weather on Neptune II. Astrophys. J. 214, 663-666.

Pollack, J. B., K. Rages, S. Pope, M. Tomasko, P. N. Romani, and S. K. Atreya 1987. Nature of the stratospheric haze on Uranus: evidence for condensed hydrocabons. J. Geophys. Res. 92, 1503715065 .

Romani, P. N. 1986. Clouds and Methane Photochemical Hazes on the Outer Planets. Ph.D. thesis, University of Michigan.

Romani, P. N., and S. K. Atreya 1984. Photochemistry of Methane in the Atmosphere of Neptune. Bull. Amer. Astron. Soc. 16, 660.

Romani, P. N., And S. K. Atreya 1986. Polyacetylene Photochemistry and Condensation on Uranus. Bull. Amer. Astron. Soc. 18, 758.

SaGan, C., and W. R. Thompson 1984. Production and condensation of organic gases in the atmosphere of Titan. Icarus 59, 133-151.

Savage, B. D., W. R. Cochran, and P. R. WesSELIUS 1980. Ultraviolet albedos of Uranus and Neptune. Astrophys. J. 237, 627-637.

Slanger, T. G. $1982.1216 \AA$ photodissociation of $\mathrm{H}_{2} \mathrm{O}, \mathrm{NH}_{3}$, and $\mathrm{CH}_{4}$. In Abstracts of the Fourth Annual Meeting of Planetary Atmospheres Principal Investigators (S. K. Atreya and D. Swartz, Eds.), pp. 129-131. University of Michigan Press.

Stief, L. J., V. J. DeCarlo, and R. J. Mataloni 1964. Vacuum-ultraviolet photolysis of acetylene. $J$. Chem. Phys. 42, 3113-3121.

Strobel, D. F. 1969. The photochemistry of methane in the Jovian atmosphere. J. Atmos. Sci. 26, 906911.

Strobel, D. F. 1973. The photochemistry of hydrocarbons in the Jovian atmosphere. J. Atmos. Sci. 30, $489-498$.

Strobel, D. F. 1975. Aeronomy of the major planets: Photochemistry of ammonia and hydrocarbons. Rev. Geophys. Space Phys. 13, 372-382.

STULL, D. R. 1947. Vapor pressure of pure substances organic compounds. Indust. Eng. Chem. 39, 517540. 
Terrile, R. J., AND B. A. SMITH 1983. The rotation rate of Neptune from ground-based CCD Imaging. Bull. Amer. Astron. Soc. 15, 858.

Tokunaga, A. T., G. S. Orton, and J. Caldwell 1983. New observational and constraints on the temperature inversions of Uranus and Neptune. Icarus 53, 141-146.

Vogel, A. I. 1948. Physical properties and chemical constitution. Part XXIII. Miscellaneous compounds. Investigation of the so-called co-ordinate or dative link in esters of oxy-acids and in nitroparaffins by molecular refractivity determinations. Atomic structural and group parachors and refractivities. J. Chem. Soc. London, 1833-1855.

WAITE, J. H., JR. 1981. The Ionosphere of Saturn. Ph.D. thesis, The University of Michigan.

Weidenschilling, S. J., AND J. S. Lewis 1973. Atmospheric and cloud structures of the Jovian planets. Icarus 20, 465-476.
West, R. A., D. F. Strobel, And M. G. Tomasko 1986. Clouds, aerosols, and photochemistry in the Jovian atmosphere. Icarus 65, 161-218.

Yung, Y. L., M. Allen, And J. P. Pinto 1984. Photochemistry of the atmosphere of Titan: Comparison between model and observations. Astrophys. $J$. Suppl. 55, 465-506.

ZiEgler, W. T. 1959. The Vapor Pressures of Some Hydrocarbons in the Liquid and Solid State at Low Temperatures. National Bureau of Standards Technical Note 4 .

Ziegler, W. T., B. S. Kirk, J. C. Mullins, and A. R. BERQuist 1964. Calculation of the Vapor Pressure and Heats of Sublimation of Liquids and Solids Below One Atmosphere Pressure. VII. Ethane. Technical Report No. 2., Eng. Expt. Station, Georgia Institute of Technology. 